\title{
A QUALIDADE DO ENSINO DA FÍSICA E O INTERESSE DE ESTUDANTES DO ENSINO MÉDIO PELA DOCÊNCIA NA ÁREA
}

\author{
Márcia Elida Domingos Prudêncio ${ }^{1}$ \\ Instituto Federal de Santa Catarina - IFSC. Araranguá, Brasil \\ Graciane Gonçalves Farias \\ Prefeitura de Araranguá. Araranguá. Brasil \\ Franciele de Souza Caetano Vieira \\ Universidade Federal de Santa Catarina - UFSC. Florianópolis, Brasil \\ Suzy Pascoali \\ Instituto Federal de Santa Catarina - IFSC. Araranguá, Brasil
}

\begin{abstract}
Resumo. Neste estudo são investigadas possíveis causas para a falta de professores na área de Física, especialmente, no Ensino Médio. O estudo teve como objetivo entender as razões que levam os estudantes de Ensino Médio a não optarem pelo curso de licenciatura em Física em seus vestibulares, apesar da demanda de mercado para professores nessa área ser superior à quantidade de profissionais disponíveis. Para realização do estudo, optou-se pela pesquisa exploratória e pela abordagem quantitativa, e os dados foram coletados por meio da aplicação de um questionário a estudantes do último ano do Ensino Médio, indagando sobre a forma adotada para trabalhar o conteúdo de Física, as preferências dos estudantes e a possibilidade de se optar pela Física como carreira profissional, entre outros aspectos. Os resultados apontaram para um interesse reduzido em relação à possibilidade de selecionar a área como futuro campo profissional, apesar de um interesse mais significativo pelo estudo da área enquanto disciplina do Ensino Médio.
\end{abstract}

Palabras-chave: Física, qualidade do ensino, atuação profissional.

\section{LA CALIDAD DE LA ENSEÑANZA DE FÍSICA Y EL INTERÉS DE ESTUDIANTES DE LA ENSEÑANZA MEDIA POR LA DOCENCIA EN ESTA ÁREA}

Resumen. Se investigan en este estudio causas posibles de un problema que afecta principalmente a las escuelas de enseñanza media: la falta de profesores en el área de la Física. Su objetivo ha sido comprender los motivos que llevan a los estudiantes de la secundaria a no aceptar o no elegir la carrera de Licenciatura en Física en su proceso de elección de la Enseñanza Superior, a pesar de que la demanda del mercado para los docentes en esta área es mayor que la cantidad de profesionales disponibles. Para realizar el estudio se ha optado por una investigación exploratoria y cuantitativa, utilizando un cuestionario para recolectar los datos en estudiantes del último año de la Enseñanza Media. Los resultados apuntan a un interés reducido en relación a la carrera profesional en Física, a pesar de existir por la asignatura.

Palabras clave: Física, educación de calidad, actuación profesional.

\footnotetext{
${ }^{1}$ Márcia Elida Domingos Prudêncio. Instituto Federal de Santa Catarina - IFSC. marcia.prudencio@ufsc.br
} 


\title{
HIGH SCHOOL PHYSICAL WITH QUALITY AND PREFERENCE IN THIS AREA OF EDUCATION
}

\begin{abstract}
In this article we study the possible causes of a problem that primarily affects high schools: the lack of teachers of physics. The aim has been to understand the reasons why high school students do not choose to study a degree in Physics, despite the market demand for teachers in this area, which is greater than the professionals available. We opted for an exploratory and quantitative methodology, using a questionnaire among students of last year of high school. The results points to a reduced interest in relation to the professional path in Physics, despite its existence as a subject.
\end{abstract}

Keywords: Physics Teaching quality education, educational formation, meaningful learning.

\section{Introdução}

Os cursos de licenciatura no Brasil foram criados nas antigas faculdades de Filosofia nos anos 1930 (Gobara e Garcia, 2007) principalmente como consequência da preocupação com a regulamentação do preparo de docentes para a escola secundária, atual Ensino Médio. Essa maneira de conceber a formação docente revela-se consoante com o que é denominado, na literatura educacional, de modelo da racionalidade técnica. Nesse modelo, o professor é visto como um técnico, um especialista que aplica na sua prática cotidiana metodologias que têm como fundamento as regras que derivam do conhecimento científico.

Para formar esse profissional entendia-se necessário um conjunto de disciplinas científicas que forneceriam as bases para sua ação, sem que isso significasse a superação de um ensino tradicional. Sem uma preocupação com a formação integral do professor, o ensino tem passado décadas permeado por uma prática pedagógica arraigada ao paradigma positivista, também conhecido como tradicional.

O paradigma positivista é vinculado aos princípios cartesianos de fragmentação do conhecimento e de dicotomia das dualidades, disseminado a partir da difusão dos posicionamentos de Descartes. Essa fragmentação do conhecimento se generaliza e se reproduz por meio da organização social e educacional e configura “... o modo de ser e de pensar dos sujeitos ...” (Santos, 2009, p. 15).

É também a partir desse paradigma que a educação prioriza a transmissão de conhecimentos historicamente acumulados, sem considerar as possibilidades de sua reconstrução ou produção nos próprios contextos educacionais. O que vale é a assimilação desses conhecimentos, por meio da memorização e da reprodução constante. (Zwierewicz, 2015, p. 12).

Apesar dos avanços educacionais, em função da influência de outros paradigmas, tais como o paradigma interpretativo, o paradigma sociocrático e o 
paradigma ecossistêmico (Moraes, 2004), problemas de década anteriores seguem atingindo as escolas no contexto brasileiro, entre os quais se destaca o déficit de professores na área de Física. Em um estudo realizado pelo Instituto Nacional de Estudo e Pesquisa Educacional (INEP, 2003), identificou-se que, dos 31.175 professores de Física do Brasil, apenas 3.095 possuíam a licenciatura na área. Dos demais, 8.981 eram formados em Matemática, 6.825 em Química, Biologia ou Engenharia, 1.837 em Pedagogia, 2.166 possuíam outra graduação e 2.822 não possuíam qualquer curso superior.

Há poucos ingressos no curso de Física, todavia esse desestímulo pode começar no Ensino Médio, onde a disciplina representa para o estudante, na maior parte das vezes, um grande desafio em função da complexidade do conteúdo e a persistência do paradigma tradicional nos processos de ensino e de aprendizagem, exigindo que ele decore fórmulas cuja origem e finalidade são desconhecidas. Neste estudo exploratório procurou-se avaliar, por meio da aplicação de questionário, as causas que levam a um número reduzido de estudantes optarem pela licenciatura, além de outras questões pertinentes e que envolvem a qualidade do ensino.

Estudos precedentes indicam que a problematização da qualidade do ensino é frequentemente discutida nos mais diversos âmbitos, pois vai além das esferas escolares, passando pelas políticas públicas e pelas ações que delas derivam, entre as quais a oferta de infraestrutura para atender as necessidades de cada contexto. Nesse sentido, Arroyo enfatiza que:

Não são as diferenças de clima, ou de região que marcam as grandes diferenças entre escola possível e impossível, mas as diferenças de classe. As políticas oficiais tentam ocultar esse caráter de classe no fracasso escolar, apresentando os problemas e as soluções como políticas regionais locais. (Arroyo, 2007, p. 21).

A esse respeito o artigo 206, inciso VII da Carta Magna, faz menção expressa à importância da qualidade da educação, tratando-a como um princípio basilar do ensino a ser ministrado, ou seja, garante o direito à educação com "padrão de qualidade" para todos (Brasil, 2013). Para Demo (2001) a educação define a qualidade nas áreas social e humana, pois ele entende que não há como chegar a elas sem educação. $\mathrm{O}$ autor ressalta ainda que a educação, que supõe qualidade formal e política, exige construção e participação, pois "... precisa de anos de estudo, de currículo, de prédios e de equipamentos, mas, sobretudo de bons professores ..." para se concretizar (Demo, 2001, p. 21).

Nesse contexto, compreende-se que, para alcançar a qualidade, é necessário investir em docentes formados efetivamente na área a que se propõe lecionar. $\mathrm{O}$ objetivo é despertar no aluno, além do interesse pela disciplina ministrada, na qual tem profundo conhecimento, a curiosidade e a admiração de uma possível futura carreira a ser seguida. 
Espera-se também que um processo de formação continuado de docentes possa estimular os estudantes a se apropriarem, construírem, socializarem, difundirem e aplicarem o conhecimento, por meio de estratégias que motivem a pesquisa e o uso do laboratório e de experiências para que compreendam conceitos da área, favorecendo a articulação teórico-prática. Nesse sentido, Grosso afirma que "As experiências forçam os estudantes a refletir e pensar nos processos envolvidos de forma científica, o que lhes desperta o interesse, dá-lhes oportunidade de vivenciar o processo de investigação científica, desenvolve sua capacidade de resolução de problemas, faz os [sic] compreender conceitos básicos e acaba por desenvolver suas habilidades." (Grosso, 2001, p. 5).

Moreira e Ostermann (1999, p. 154) registram que uma das condições para ocorrência de aprendizagem significativa é que o material a ser aprendido seja relacionável (ou incorporável) à estrutura cognitiva do aprendiz, de maneira não arbitrária e não literal. Um material com essa característica é dito potencialmente significativo. Ao trabalhar a atividade experimental, relacionando o conteúdo com o cotidiano do aluno, por exemplo, o professor estimula o aluno a questionar e participar mais das aulas.

De acordo com Ausebel, a compreensão genuína de um conceito ou proposição implica a posse de significados claros, precisos, diferenciados e transferíveis. Porém, ao se testar essa compreensão, simplesmente pedindo para o aluno que diga quais os atributos essenciais de um conceito ou os elementos essenciais de uma proposição, pode-se obter apenas respostas mecanicamente memorizadas. (Moreira e Ostermann, 1999, p. 154).

Ministrar aulas por meio de estratégias diferenciadas é de suma importância, ainda mais quando se tem a oportunidade de envolver as escolas públicas em projetos educacionais como os vinculados ao Programa Institucional de Bolsa de Iniciação à Docência (PIBID), que incorpora acadêmicos de licenciatura nas atividades da escola, para propor e realizar atividades experimentais e projetos interdisciplinares. Os estudantes têm a chance de participar e aprender algo que motiva sua ida à escola, interessando-se por um ensino que supera a prática centrada no quadro e na fala do professor. Além disso, as atividades desenvolvidas pelos "Pibidianos" (termo criado para identificar estudantes vinculados às bolsas oferecidas pelo PIBID) têm um referencial de ensino bem definido e que é fortalecido nos cursos que frequentam, o que possibilita uma evolução conceitual importante.

Em contrapartida, em um estudo realizado sobre o ensino de Física no Brasil, constatou-se que alguns dos problemas atuais sempre se fizeram presentes: percebeu-se um ensino expositivo, geral, superficial, baseado na memorização e com excessiva dependência dos manuais didáticos (Gobara e Garcia, 2007, p. 519).

Além desse problema, dois dos atuais pontos de preocupação em relação aos professores são a extensa carga horária e a falta de material didático. $\mathrm{O}$ excesso de 
trabalho e a falta de recursos têm colaborado para que o professor deixe de investir em experimentos que facilitariam a compreensão dos conteúdos. Também tem se discutido a necessidade de rever o próprio conteúdo previsto para o Ensino Médio, questão que tem mobilizado a elaboração da Base Nacional Comum Curricular (Brasil, 2015). Por outro lado, a escassez de infraestrutura, especialmente em relação aos laboratórios, tem sido indicada como aspecto que integra uma conjuntura não favorável ao interesse dos estudantes pela área da Física.

Da mesma forma que valorizamos o uso de laboratórios para o desenvolvimento de aulas práticas, enfatizamos o uso de laboratórios de informática, uma vez que a internet disponibiliza softwares relacionados aos conteúdos trabalhados no currículo de Física. Nesse sentido, Freire parte do princípio que o compromisso da educação é “.... com o homem concreto, com a causa de sua humanização, de sua libertação ... sem ... prescindir da ciência, nem da tecnologia, com as quais ... se instrumentaliza." (Gobara e Garcia, 2007, p. 22-23).

Diante dessa afirmativa, entende-se que a ciência e a tecnologia são fundamentais para a educação e a sociedade, já que uma depende da outra. Contudo, para aproveitar o potencial tecnológico e estimular a permanência dos estudantes, são necessárias medidas educacionais urgentes, que tornem a aprendizagem mais significativa e articulada aos problemas da realidade, especialmente em cursos em que a evasão é mais acentuada em função de vários fatores, entre os quais a complexidade do conteúdo.

Há em questão também o perfil socioeconômico, que obriga os estudantes a estudarem e trabalharem concomitantemente. Desse modo, a falta de expectativa que deriva de baixos salários, somada ao declínio do status social da profissão, fazem com que as licenciaturas vivam em constante crise, tanto nas instituições públicas quanto nas privadas. Tendo em vista esses problemas, é preciso criar estratégias para que os estudantes possam permanecer no curso e se formem no período previsto.

Faz-se necessário dar sustentabilidade, conceder auxílios e bolsas e outras condições de estudo, além de criar equipes de professores que possam dedicar-se sistematicamente aos cursos, a fim de proporcionar condições dignas para a aprendizagem. Também é necessário desenvolver ações que contemplem as etapas que antecedem o Ensino Superior, trabalhando para a melhoria de qualidade nas instituições de Ensino Fundamental e Médio (Gobara e Garcia, 2007), por meio de estratégias que colaborem para a superação do paradigma de educação tradicional.

\section{Método}

A escola pesquisada pertence ao quadro da rede de ensino pública estadual, localizada no Centro de Araranguá (Santa Catarina, Brasil). A instituição oferta curso de Ensino Médio e Técnico, e o profissionalizante Magistério. Possui laboratório de 
informática, sala de professores, salas de aula, sala de vídeo, auditório, refeitório, ginásio de esportes, quadra de futebol e vôlei, secretaria, sala de apoio pedagógico, entre outros espaços. Contudo, foi observado que ainda há falta de infraestrutura para as práticas experimentais e professores capacitados para o desenvolvimento de aulas que articulem teoria e prática.

Decidiu-se aplicar um questionário a estudantes que frequentavam o último ano do Ensino Médio na referida instituição, por ser um momento oportuno para definir o curso superior que pretendiam ingressar. Como uma das intenções da pesquisa foi avaliar se existe interesse pela área da Física, optou-se como campo de pesquisa esse contexto.

Para realização da pesquisa, adotou-se o método exploratório e a abordagem quantitativa, definindo-se pela aplicação de um questionário. $\mathrm{O}$ instrumento foi aplicado a 33 (trinta e três) estudantes em sala de aula e na presença de um professor, que cedeu um determinado tempo para que eles pudessem responder e entregar o questionário individualmente. $\mathrm{O}$ tratamento dos dados coletados possibilitou o alcance dos resultados apresentados na sequência.

\section{Resultados e discussão}

O questionário foi composto por seis itens, que envolviam, entre outros aspectos, o interesse pela área da Física enquanto disciplina do Ensino Médio e a possibilidade de optar profissionalmente pela área da Física. Espera-se que os resultados se transformem em indicativos para possíveis encaminhamentos no sentido de valorização da área, na melhora da qualidade do ensino ofertado e na elevação do interesse dos estudantes em frequentar um curso superior que os capacite para atuar como professores de Física conscientes da necessidade de articular o ensino às demandas da realidade.

\section{- Interesse dos estudantes na disciplina de Física}

Os resultados obtidos na questão refutam a hipótese do desinteresse generalizado dos estudantes em relação à área. Apesar de inúmeras dificuldades, observa-se que $51,5 \%$ dos estudantes possuem interesse pela disciplina de Física, conforme registrado no Gráfico 1. 


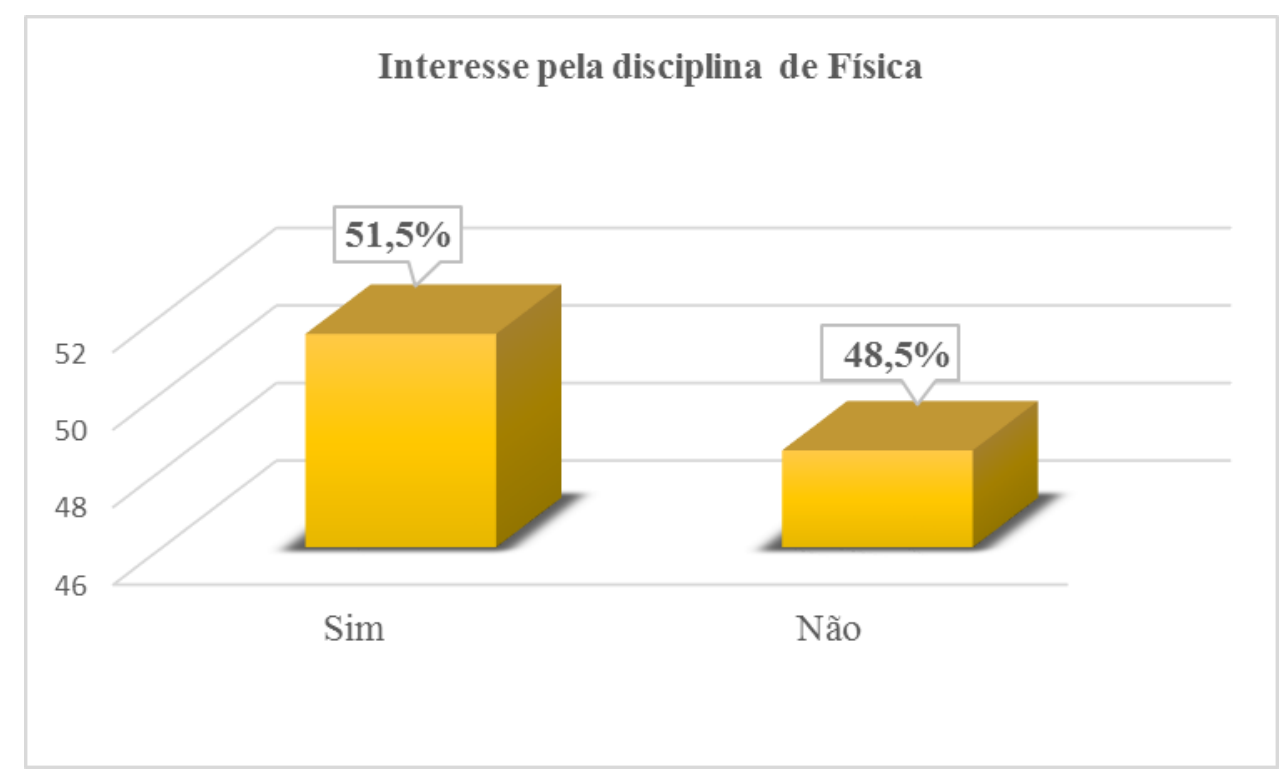

Gráfico 1. Interesse dos estudantes pela disciplina de Física.

O interesse demonstrado por uma parte substancial dos estudantes estimula reflexões sobre o que os leva a agir dessa forma. Apesar das demandas que envolvem o Ensino Médio no contexto brasileiro, esse interesse nos motiva a pensar que a área poderia obter mais destaque se houvesse mais investimento na infraestrutura e na formação docente, pois para Bevilacqua e Silva o envolvimento é conquistado “... com o desenvolvimento do trabalho experimental. Os estudantes têm sua curiosidade e interesses estimulados com a possibilidade de utilização de materiais diferentes e pelo desenvolvimento da prática." (Bevilacqua e Silva, 2007, p. 90). Nas aulas em que o estudante pode se implicar nas tarefas, articulando teoria e prática, há uma tendência à participação mais efetiva e à consequente ampliação das possibilidades de aprendizagem.

Da mesma forma, é preocupante o número expressivo de estudantes não interessados em uma área, enquanto existe um distanciamento entre conteúdos curriculares e demandas da realidade. $\mathrm{O}$ fato de a escola reforçar uma “... visão descontextualizada e simplificadora, difundida pela ciência moderna, tornou-se hegemônica ao longo dos últimos 400 anos ..." (Santos, 2009, p. 18) e tem dificultado vincular conteúdos curriculares e a realidade dos estudantes e seus entornos.

\section{- Interesse dos estudantes pelas estratégias didáticas diversificadas}

$\mathrm{Na}$ segunda pergunta foi questionado o nível de interesse dos estudantes por diferentes estratégias didáticas utilizadas pelos professores: apresentação expositiva; levantamento de questionamentos por parte dos estudantes; levantamento de argumentos dos estudantes; atividades solucionadas pelo professor; atividades solucionadas pelos estudantes; pesquisas em livros didáticos; pesquisas na internet; 
experiências realizadas pelo professor; experiências acessadas via internet; experiências realizadas pelos estudantes.

Os resultados indicaram que $2,09 \%$ dos estudantes se interessam por experiências apresentadas via internet, 4,06\% por pesquisas nos livros, 6,09\% por comentários na aula, $9,12 \%$ por pesquisas na internet, $14,19 \%$ por exercícios resolvidos pelo professor, $14,21 \%$ por exercícios resolvidos pelos estudantes, 21,27\% por perguntas abertas, 28,97\% por apresentação expositiva pelo professor, conforme registrado no Gráfico 2. Entre as possíveis interpretações, destacamos dois aspectos: o primeiro é o reduzido interesse por atividades que envolvem a internet, fato que pode ser ocasionado pelo desconhecimento das possibilidades oferecidas por ela; o segundo é o interesse significativo por exercícios resolvidos pelos professores e por aulas expositivas, situações que demonstram um perfil de estudantes adaptados a um processo mais tradicional de ensino.

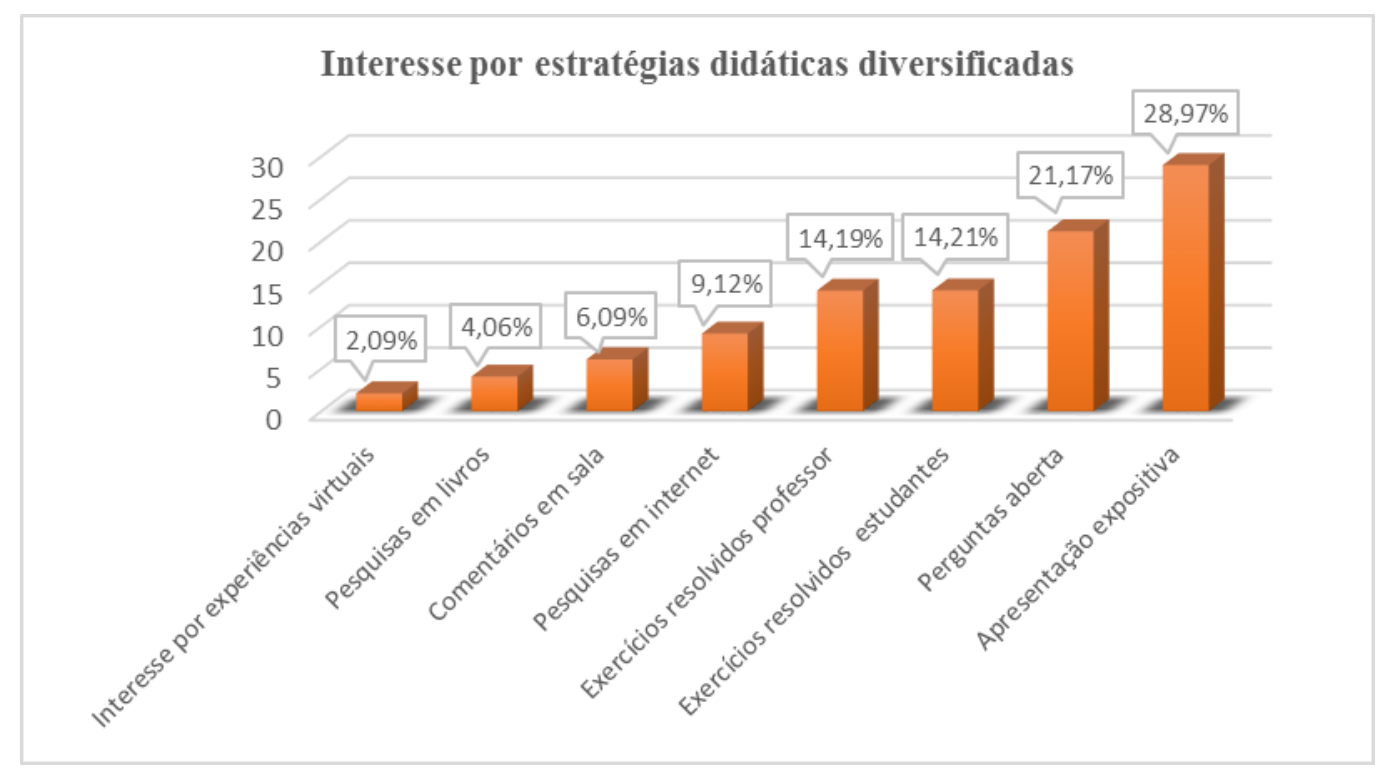

Gráfico 2. Interesse dos estudantes por estratégias didáticas diversificadas.

A influência secular do paradigma positivista, destacada por Santos (2009), sustenta a permanência de formas de ensinar, sem que se percebam outras alternativas. Em contrapartida, vários são os autores contemporâneos que investem em outras possibilidades educacionais, entre os quais Moraes (2004), Morin (2011, 2014a, 2014b), Nicolescu (2014), Pineau (2014), Pinho, M. V. R. S. Suanno e J. H. Suanno (2015), Santos (2009), Torre (2012, 2013), Zwierewicz (2009, 2013, 2015), entre outros. Além de pressupostos teóricos, parte dos referidos autores descreve experiências práticas amparadas pelo paradigma ecossistêmico. 


\section{- Causas do desinteresse dos estudantes em frequentar o curso de licenciatura em} Física

Ao serem questionados sobre os motivos que levariam uma pessoa a não escolher a possibilidade de frequentar um curso superior de Física, a maior parte dos estudantes indicou dificuldades na aprendizagem do conteúdo e o fato de não gostar da área, bem como a dificuldade de trabalhar na docência: 4,09\% apontaram que o professor não é reconhecido na sociedade, $6,07 \%$ indicaram não conhecer o curso de Ensino Superior, 6,09\% acenaram para os baixos salários dos professores, $6,12 \%$ destacaram a falta de recursos nas escolas para ensinar com qualidade, 13,07\% concluíram que se identificam com o ensino, 17,10\% destacaram a dificuldade de trabalhar com estudantes atualmente, 20,08\% ressaltaram não gostar da Física, 27,38\% indicaram que a aprendizagem da Física é complexa. A dificuldade na aprendizagem, indicada por um número considerável de estudantes, denota a necessidade de rever a prática pedagógica, mesmo que na questão anterior muitos estudantes tenham indicado como estratégias de preferências algumas que integram o paradigma positivista.

Dessa forma, de um lado está a dificuldade em aprender e, de outro, a falta de perspectivas em relação a práticas alternativas, já que o ensino não se restringe a uma metodologia exclusiva. Nesse contexto, a utilização do ensino tradicional, centrado no uso do quadro de giz e no uso exclusivo de um livro didático, sem dar condições para que o aluno construa seu próprio conhecimento, impõe uma forma linear ao processo de ensino e de aprendizagem, eliminando possibilidades mais criativas e envolventes.

Saber ensinar não é transferir conhecimento, mais criar possibilidades para a sua própria produção ou sua construção. Quando entro em uma sala de aula devo estar sendo um ser aberto a indagações, à curiosidade, às perguntas dos estudantes, as suas inibições; um ser crítico e inquiridor, inquieto em face da tarefa que tenho - a de ensinar e não a de transferir conhecimento. (Freire, 1996 p. 47).

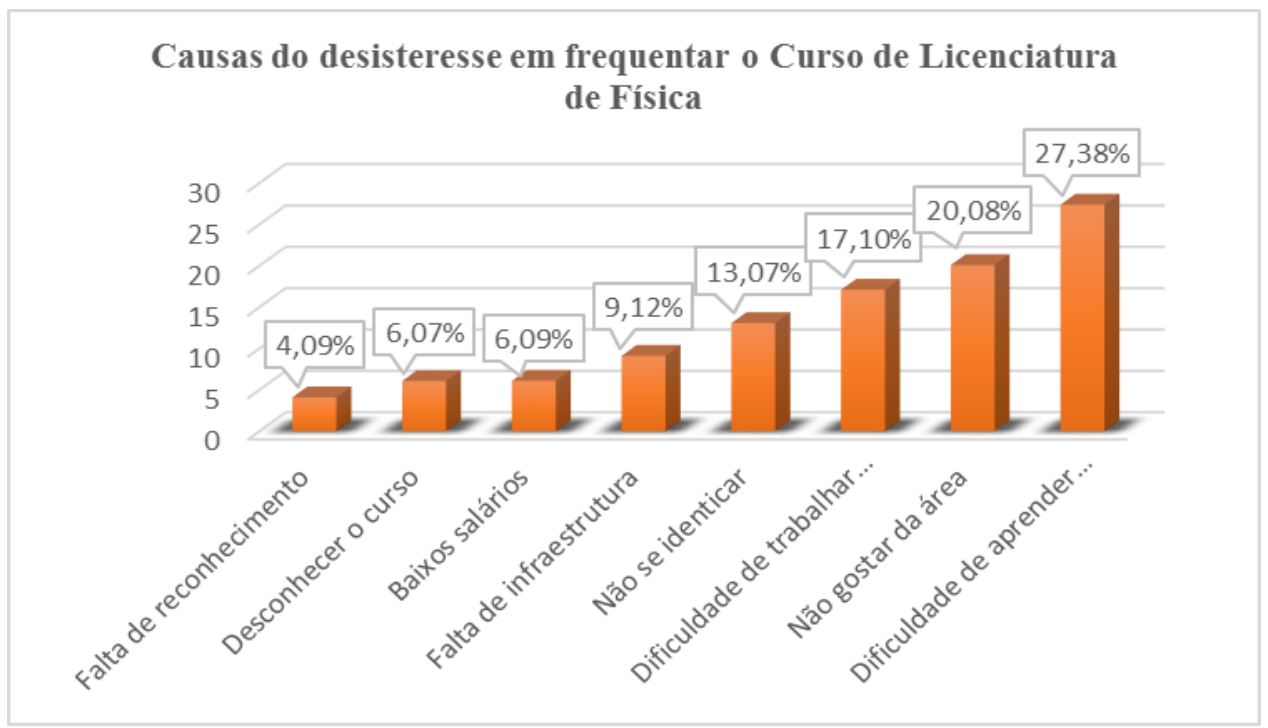

Gráfico 3. Causas do desinteresse dos estudantes em frequentar o curso de licenciatura em Física. 


\section{- Causas que motivam a opção pela docência na área da Física}

Ao serem questionados sobre os motivos que levariam uma pessoa a optar pela docência na área da Física, os resultados indicaram que, para 2,09\% dos estudantes, isso se deve à influência dos pais, $2,18 \%$ por proximidade de sua casa, $4,06 \%$ porque não se importa com baixos salários, $7,17 \%$ porque gosta de trabalhar com adolescentes, $10,15 \%$ porque a área das exatas facilita o acesso ao emprego, 15,17\% porque Física explica a natureza, $15,24 \%$ porque quer muito lecionar, 43,49\% porque gosta de cálculo, conforme registrado no Gráfico 4. Possivelmente as respostas que indicam uma preferência acentuada pelo cálculo estejam impregnadas pela ideia de que a Física está restrita a essa condição, indicando um conceito reducionista em relação à área, que envolve a natureza, a acústica, o eletromagnetismo, a termodinâmica, a óptica, entre outras questões.

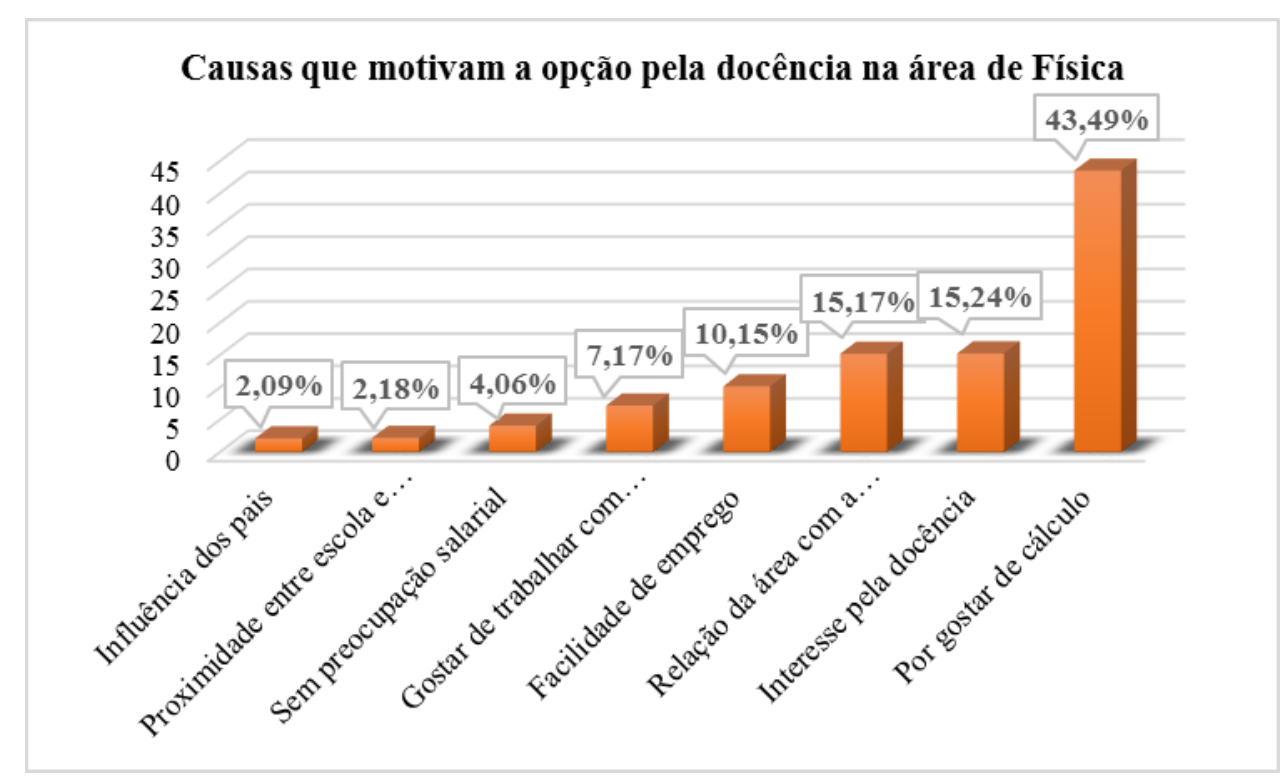

Gráfico 4. Causas que motivam a opção pela docência na área da Física

\section{- Interesse em frequentar o curso de licenciatura em Física}

Ao serem questionados sobre o interesse em frequentar um curso de licenciatura em Física, 93,94\% dos estudantes responderam que não e somente 6,06\% responderam que sim, conforme dimensionado no Gráfico 5.

O resultado é preocupante, já que existe uma carência histórica de profissionais na área, conforme já indicava um estudo realizado no início do século XXI, pelo INEP (2003), quando se identificou que, dos 31.175 professores de Física do Brasil em 2003, apenas 3.095 possuíam a licenciatura da disciplina. 


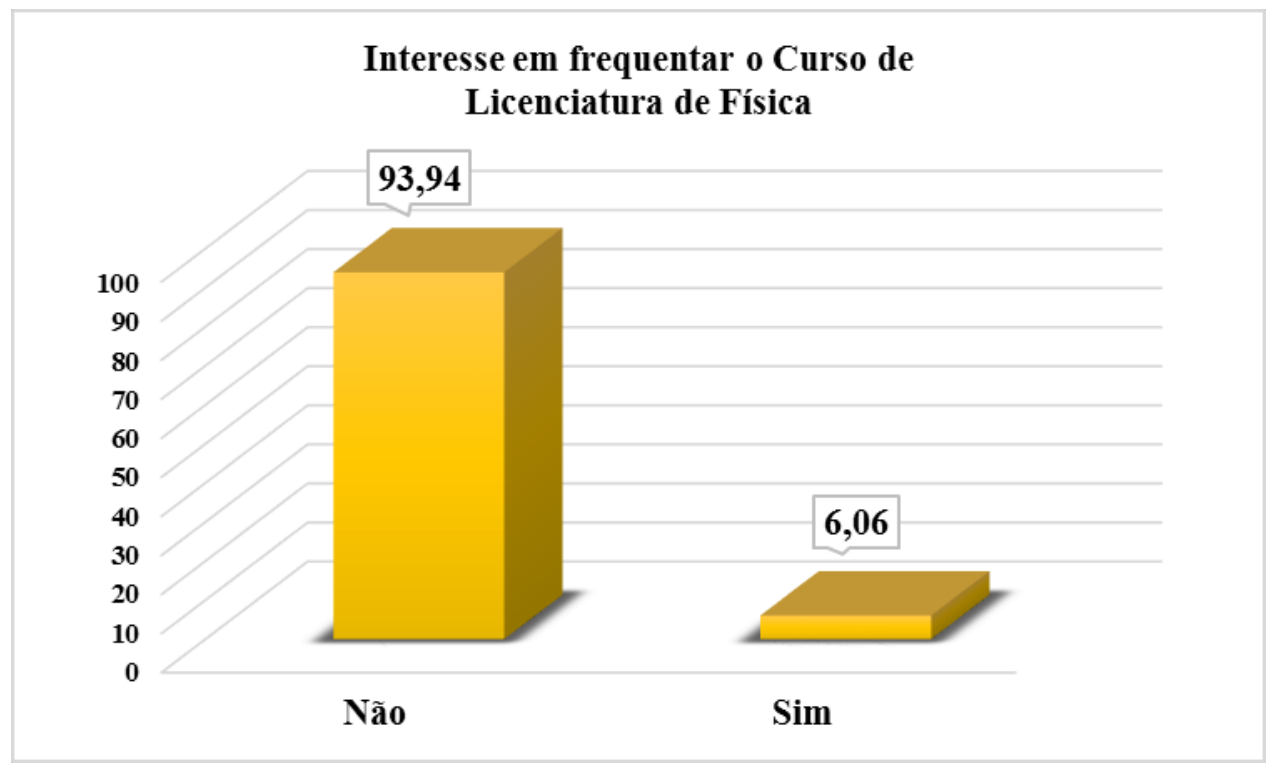

Gráfico 5. Interesse em frequentar o curso de licenciatura em Física.

\section{- Interesse em prestar vestibular para o curso de licenciatura em Física}

Ao serem questionados sobre o interesse de prestar vestibular para o curso de licenciatura em Física no final do ano letivo ou em outro momento, a maioria dos estudantes respondeu que não, indicando mais uma vez um desinteresse pela área, conforme pode ser observado no Gráfico 6. A opção mais acentuada foi a de que $84,85 \%$ não prestariam o vestibular para o curso de licenciatura em Física. Somente $15,15 \%$ responderam que sim.

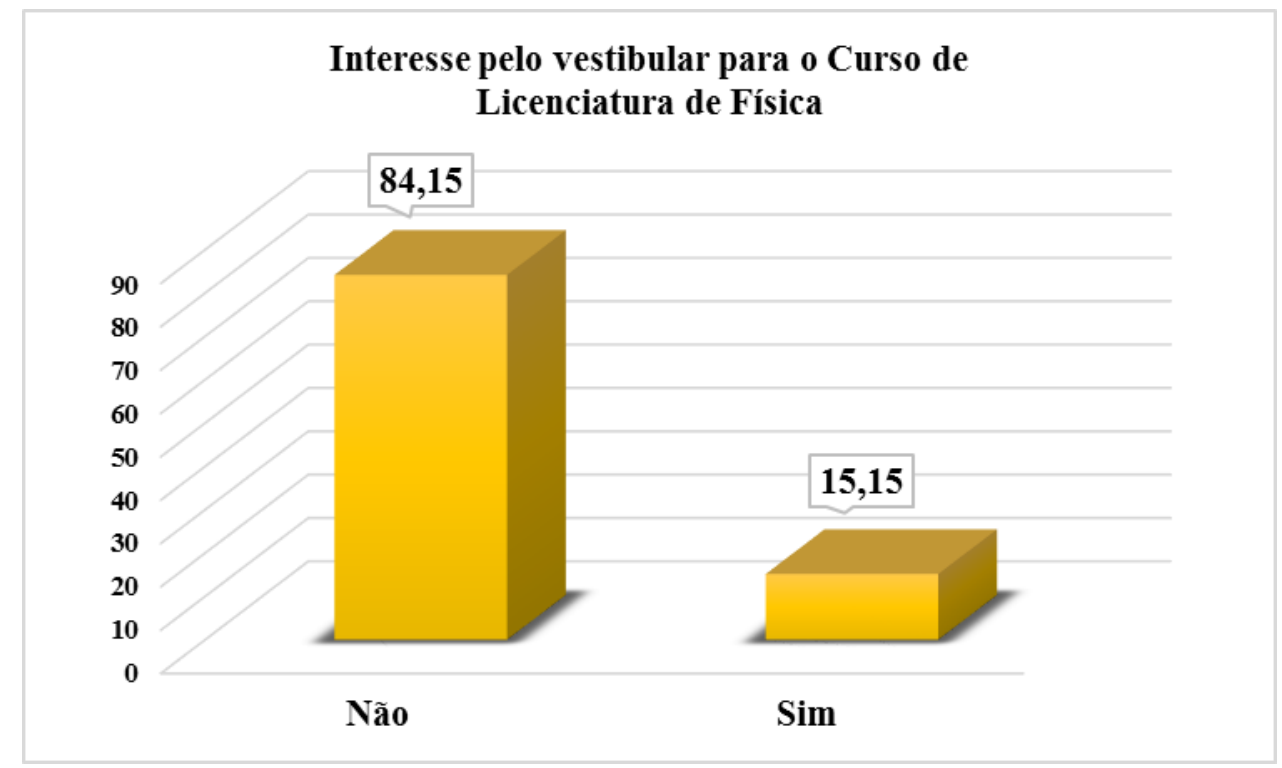

Gráfico 6. Interesse em prestar vestibular para o curso de licenciatura em Física.

Respostas como esta indicam a necessidade de se repensar a educação, atentando para a repercussão do paradigma positivista, ou pelo tradicional ensino "bancário", 
indicado por Freire (1996), por meio do qual o professor centra sua prática na transmissão de conteúdos que o estudante precisa absorver e reproduzir. Essa prática se caracteriza por uma rotina permeada pelo registro de uma diversidade de fórmulas no quadro, sem que os estudantes tenham clareza da origem. O processo avaliativo, precedido por essa prática, requisita a memorização das tais fórmulas e desmotiva o interesse pela área das exatas.

Em contrapartida, experimentos diversificados, desenvolvidos por professores que exploram a capacidade criativa, motivam os estudantes. Dessa forma, valer-se de tendências pedagógicas contemporâneas, vinculadas à criatividade e à inovação, podem facilitar a articulação teórico-prática, ampliando as possibilidades para a compreensão do processo e a utilização das fórmulas em atividades vinculadas à realidade, superando um ensino focalizado no comportamento repetitivo e controlado.

Nesse contexto, é de suma importância que os profissionais priorizem a formação continuada. Independentemente de ser promovida ou não por uma entidade educacional externa, é indispensável que esse processo se caracterize por uma formação-ação, termo utilizado por Zwierewicz (2015) para destacar a importância de os programas envolverem os profissionais em um movimento de ressignificação da própria prática, permeando a atividades por palestras, planejamento, socialização de experiências e ações que valorizem as práticas criativas desenvolvidas.

\section{Conclusão}

Para levantamento das razões que levam os estudantes de Ensino Médio a não optar pelo curso de licenciatura em Física em seus vestibulares, apesar da demanda de mercado para professores nessa área ser superior à quantidade de profissionais disponíveis, encontramos no questionário o meio mais propício para coleta de dados na realidade pesquisada. Por meio de sua aplicação, pudemos concluir que um número expressivo de estudantes gosta da disciplina de Física, apesar do contexto desfavorável e do desinteresse pela profissão docente na área.

$\mathrm{O}$ interesse poderia ser ampliado se houvesse mais investimento em materiais e na construção de laboratórios para processos de ensino e de aprendizagem que articulem teoria e prática, fazendo-se valer o direito de acesso a um ensino de melhor qualidade. Como já mencionado, há um interesse mais expressivo dos estudantes por aulas que incluem atividades práticas.

Por outro lado, é indispensável que os professores exercitem sua capacidade criativa, com empenho para trabalhar também com os recursos disponíveis, pois isso poderia elevar o interesse, o aprofundamento dos conhecimentos e a elevação do rendimento escolar. Nesse sentido, sugere-se que os professores aprofundem seus conhecimentos pedagógicos para poder propiciar uma aprendizagem mais significativa 
para o aluno, utilizando-se inclusive de possibilidades disponibilizadas em ambientes virtuais.

O fato de os estudantes acreditarem que uma pessoa escolhe ser um professor de Física porque gosta de cálculo provavelmente acontece pela dificuldade de compreender o conceito de Física, em função de como a disciplina é trabalhada. As metodologias tradicionais distanciam o ensino da Física de aspectos a ela diretamente vinculados - a natureza, o céu, o mar, o vento, o funcionamento dos eletrodomésticos etc. -, tornando a aprendizagem abstrata e vazia de sentido.

A negação da articulação entre conteúdos curriculares e demandas da realidade reduz o interesse pela opção profissional na docência na área da Física. Se a prática pedagógica minimiza o interesse dos estudantes no momento em que frequentam as aulas de Física, consequentemente, o interesse por tornar-se um profissional da área é reduzido. Como um estudante poderá escolher um curso em uma área que ainda trabalha de forma tradicional, enquanto a dinamicidade é uma das características da realidade atual? Assim, destaca-se também a necessidade de investir na formação de estudantes que persistem nos cursos de licenciatura em Física, pois vivenciaram experiências formativas que podem ressignificar os futuros trabalhos em sala de aula, transformando a prática pedagógica que subsidia seu ensino.

A partir do momento em que se ingressa no curso de licenciatura, pode-se afirmar que se abre uma nova visão em relação à área de Física, desde que haja um amparo em paradigmas educacionais inovadores e que motivem a articulação entre teoria e prática. Nesse sentido, há emergência em superar a realidade centrada no ensino tradicional.

\section{Referências}

Arroyo, M. G. (2007. Da escola carente à escola possível. 6. ed. São Paulo: Loyola.

Bevilacqua, G.D e Silva, R, C. (2007). O ensino de Ciências na $5^{\text {a }}$ Série através da experimentação. Revista Ciências e Cognição, 10, 84-92.

Brasil. (1988). Constituição da república federativa do Brasil de 1988. Disponível em<http://www.planalto.gov.br/ccivil_03/constituicao/constitui\%C3\%A7ao.htm>. Acesso em: 29 ago. 2013.

Brasil, Coordenação de Aperfeiçoamento de Pessoal de Nível Superior - CAPES (2013). Programa Institucional de Bolsa de Iniciação à Docência - PIBID. Disponível em:< http://www.capes.gov.br/educacao-basica/capespibid>. Acesso em 10 set. 2013.

Brasil (2015). Base Nacional Comum Curricular - BNC. Brasília: MEC. Recuperado em 28 de julho de 2015, de http://basenacionalcomum.mec.gov.br/\#/site/conheca 
Demo, P. (2001). Educação e qualidade. 6. ed. São Paulo: Papirus.

Freire, P. (1996). Pedagogia da autonomia: saberes necessários à prática educativa. São Paulo: Paz e Terra.

Gobara, S. T.; Garcia, J. R. (2007). As licenciaturas em física das universidades brasileiras: um diagnóstico da formação inicial de professores de física". Revista Brasileira de Ensino de Física, 29(4), 519-525.

Grosso, A. B. (2006). Eureka! Práticas de Ciências para o Ensino Fundamental. 2 ed. São Paulo: Cortez.

INEP (2003). Sinopse do Censo dos Profissionais do Magistério da Educação Básica2003. Brasília: MEC.

Moraes, M. C. (2004). Além da aprendizagem: um paradigma para a vida. In M. C Moraes e S. Torre (Org.). Sentipensar: fundamentos e estratégias para reencantar a educação. (pp. 19-25). Petrópolis: Vozes..

Morin, E. (2011). La vía: para el futuro de la humanidad. Barcelona: Paidós.

Morin, E. (2014a). Enseigner à vivre: manifeste pour changer l'éducation. Paris: Actes Sud.

Morin, E. (2014b). Pour une politique de la villeau XXIème siècle: Contributionau 7ème Forum Urbain Mondial - Carta Medellín - WUF7 - 2014. Medellín: Fórum Urbano Mundial.

Moreira, M. A. e Ostermann, F. (1999). Teorias Construtivistas. Porto Alegre: Instituto de Física - UFRGS.

Moreira, M. A. (2001). Aprendizagem Significativa: a teoria de David Ausubel. São Paulo: Centauro.

Nicolescu, B. (2014). Transdisciplinariedad: passado, presente y futuro. In A. C. Martinez e P. Galvani (Org.). Transdisciplinariedad y formación universitaria: teorías y prácticas emergentes. (pp. 45-90). Puerto Vallarta: CEUArkos.

Pineau, G. (2014). Las reflexiones sobre las prácticas: el corazón de la vuelta reflexiva. In A. C. Martinez e P. Galvani (Org.). Transdisciplinariedad y formación universitaria: teorías y prácticas emergentes. (pp. 91-114). Puerto Vallarta: CEUArkos.

Pinho, M. J., Suanno, M. V. R. S. e Suanno, J. H. (Org.) (2015). Projetos Criativos na prática pedagógica: cantar e encantar a aprendizagem. Goiânia: Espaço Acadêmico.

Santos, A. (2009). Complexidade e transdisciplinaridade em educação: cinco princípios para resgatar o elo perdido. In A. Santos e A. Sommerman. Complexidade e transdisciplinaridade: em busca da totalidade perdida. (pp. 15-38). Porto Alegre: Sulina. 
Silva, M. B. G. (2011). Organização curricular da Escola Avaliação da Aprendizagem. Recuperado em 17 de setembro de 2011, de http://www.pead.faced.ufrgs.br/sites/publico/eixo5/organizacao_escola/modulo2/t exto_base.pdf.

Torre, S. (2013). Movimento de escolas criativas: fazendo parte da história de formação e transformação. In M. Zwierewicz (Org.). Criatividade e inovação no Ensino Superior: experiências latino-americanas em foco. (pp. 139-163). Blumenau: Nova Letra.

Torre, S. (2012). Criadores na adversidade e na crise: qual é o segredo? In S. Torre e M. Zwierewicz (Org.). Criatividade na adversidade: personagens que transformaram situações adversas em oportunidade. (pp. 19-48). Blumenau: Nova Letra.

Zwierewicz, M. (2009). Escolas Criativas: escolas que aprendem, criam e inovam. In M. Zwierewicz e S. Torre (Org.). Uma escola para o século XXI: escolas criativas e resiliência na educação. (pp. 55-70). Florianópolis: Insular, 2009.

Zwierewicz, M. (Org.) (2013) Criatividade e inovação no Ensino Superior: experiências latino-americanas e europeias em foco. (pp. 9-17). Blumenau: Nova Letra.

Zwierewicz, M. (2015). Metodologia do Ensino Superior. Florianópolis: Senac.

Data de recepção: 27/10/2014

Data de revisão: $30 / 10 / 2015$

Data do aceite: 29/12/2015 
Prudêncio, M. E. D.; Farias, G. F.; Vieira, F. de S. C. e Pascoali, S. 